\title{
Emociones, amor y experiencias migratorias de españoles e italianos calificados en México
}

\section{Emotions, love and and migration experiences of skilled Spaniards and Italians in Mexico}

\author{
Anna Ortiz Guitart \\ Departamento de Geografía \\ Universitat Autónoma de Barcelona, Barcelona. España \\ ORCID: http://orcid.org/o0oo-0002-6016-5136 \\ DoI: http://dx.doi.org/I0.28928/revistaiztapalapa/842018/atc5/ortizguitarta
}

\section{Resumen}

Este artículo se centra en el papel que juegan las emociones en la decisión de migrar, en la de permanecer y en la de regresar de un grupo de migrantes españoles e italianos a México. A partir de una investigación cualitativa y del análisis de aspectos emocionales relacionados con sus vínculos de pareja, familiares y de amistad, creados tanto en su lugar de origen como en su lugar de destino, este artículo explora las experiencias emocionales de amor y migración de estas personas. Se constata, entre otros aspectos, que las parejas toman la decisión de ir a vivir a México más en función del proyecto laboral de los hombres que del de sus esposas. A menudo éstas, aun teniendo un buen trabajo remunerado en España e Italia, abandonan sus trabajos para que sus esposos tengan mejores oportunidades para encontrar un trabajo acorde a sus cualificaciones académicas en México.

Palabras clave: amor, familia, migración internacional, México, Sur de Europa

\begin{abstract}
This article explores the role of emotions in deciding to migrate, remain and come back of a group of Spanish and Italian immigrants in Mexico. It takes a qualitative approach to the analysis of emotional aspects related to their love, family and friendship bonds, which they have build in their countries of origin or destination. It focuses on the emotional experiences of love and migration of these people. Interviews reveal that couples' decisions on living abroad are more based on the labour perspectives of men. Wives quite often quit their well-paid jobs in Spain and Italy so that their husbands can have better job opportunities, matching their academic background.
\end{abstract}

Keywords: love, family, international migration, Mexico, Southern Europe

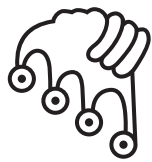

IZTAPALAPA

Agua sobre lajas

*anna.ortiz@uab.cat 
$1 \begin{aligned} & \text { mor, alegría, tristeza, soledad, arraigo, desarraigo... son algunas de las } \\ & \text { emociones que aparecen a menudo en relatos y películas de ficción sobre } \\ & \text { experiencias migratorias. Para poner algún ejemplo tenemos la novela }\end{aligned}$ Días de amor y engaños de Alicia Giménez Bartlett publicada en 2006 y la película $10.000 \mathrm{~km}$ del director Carlos Marqués-Marcet, ganadora del festival de Málaga de 2014. Por un lado, la novela narra las vivencias de un grupo de ingenieros españoles y sus esposas que van a vivir temporalmente y por razones laborales a una colonia situada en una zona rural de México. La novela describe el desarrollo de la vida cotidiana de las mujeres, la configuración de sus redes de amistad y la transformación de sus relaciones de pareja. Por el otro, la película cuenta la historia de un amor a distancia. Una pareja vive felizmente en Barcelona cuando a ella le hacen una oferta profesional irrechazable para ir a trabajar un año a Estados Unidos. Confiando en la fortaleza de su relación deciden afrontar el reto de los miles de quilómetros de distancia que los separan. La película ofrece la posibilidad de observar cómo evoluciona una relación de pareja a partir de la falta de cotidianeidad, de la distancia física, del descubrimiento de otro mundo y de la comunicación a través de Skype.

Las emociones que brotan de estos ejemplos de ficción pueden servirnos de pretexto para introducir la investigación que aquí se presenta. ¿Qué papel juegan el afecto y las emociones para entender aspectos esenciales, pero hasta hace poco olvidados, de las migraciones internacionales?. Muchas personas migran porque se enamoran y deciden ir a vivir al país de la pareja y una vez en éste tienen hijos, buscan y encuentran un trabajo, tejen nuevas amistades $y$ relaciones laborales, mantienen el contacto a distancia con su familia y amistades, sueñan con regresar o con sentirse a gusto en su nueva destinación. En nuestra vida cotidiana y debido a nuestra relación con otras personas surgen emociones que, como nos recuerdan Boiger y Mesquita (2012), son alimentadas por interacciones cotidianas y lazos interpersonales.

Las ciencias sociales tienen en cuenta cada vez más las emociones ya que éstas forman parte de la vida cotidiana (Boccagni y Baldassar, 2015). De esta forma, en los últimos años, la intersección entre las emociones y la movilidad permite aproximarnos al estudio de las migraciones desde una dimensión más humana. 
$\mathrm{Al}$ analizar las trayectorias de hombres y mujeres migrantes $\mathrm{y}$, más concretamente, de sus motivaciones a la hora de migrar, deberían considerarse dimensiones varias y coexistentes como las oportunidades del mercado laboral (Raghuram, 2004), la mejora del estatus económico, la resistencia a la opresión socioeconómica y de género, el deseo de experimentar nuevos ambientes o la expresión libre de la sexualidad. Más aún, las personas pueden tener distintas respuestas emocionales hacia la movilidad, y éstas están significativamente influenciadas por las condiciones socio-económicas, políticas y culturales de la migración (Gallo, 2015). Si queremos entender las complejidades sociales, económicas, políticas y experienciales de la movilidad humana y el sentido de pertenencia, será necesario incluir las emociones (Svasek, 2010; Wood y Waite, 20II), porque como señala Ahmed (200I: II), "emoción' y 'movimiento' van íntimamente conectados: no sólo la palabra 'emoción' proviene del latín 'emovere', que significa 'para ser movido', sino que las emociones son 'lo que nos mueve' y 'lo que nos hace sentir, lo que nos ata al lugar, o nos da un lugar para vivir" (citado en Huang y Yeoh, 2007).

Este artículo tiene como objectivo comprender el papel que juega el amor y las emociones en la decisión de migrar, en la de permanecer en el lugar de destino y en la de regresar al país de origen. El artículo se estructura en cuatro partes. La primera hace una aproximación teórica a las temáticas relacionadas con la intersección entre las emociones y la migración a partir de las publicaciones más recientes de este ámbito. A continuación se presenta la metodología cualitativa utilizada, así como los perfiles de las personas entrevistadas. En tercer lugar, se muestran los principales resultados del estudio, para terminar con una serie de reflexiones finales.

\section{Emociones y migración‡ punto de partida teórico ${ }^{1}$}

En este apartado nos acercaremos al estudio de la relación entre las emociones y la migración desde tres miradas que nos permitirán entender mejor las dinámicas y los procesos que configuran esta relación. En primer lugar, nos referimos al amor como principal motivación para migrar. En segundo lugar, a la amistad como una nueva forma de intimidad forjada en la distancia. Y en tercer lugar, a las nuevas subjetividades que surgen en los espacios y lugares de destino. Sin ánimo de exhaustividad pero con la voluntad de dar a conocer los últimos avances sobre la materia,

1 En el artículo de Mendoza, Staniscia y Ortiz (2016) puede encontrarse una primera versión resumida sobre este tema. 
presentamos algunos trabajos publicados en los últimos años que nos ayudan a profundizar sobre las dinámicas afectivas y emocionales de las personas migrantes.

\section{"Yo, por amor, lo he dado todo"ः migraciones por amor}

Yo, en Barcelona, ganaba más que él, bastante más. Lo que pasa es que él llegó a ser director comercial y le ofrecieron un puesto más alto y para él salir de Barcelona le suponía una promoción, un reto... (...). Yo estaba muy bien considerada, cobraba muchísimo, tenía mi equipo, tenía mi horario... estaba en el mejor momento profesional y entonces fue cuando Juan ${ }^{2}$ me dijo "vámonos" (...). Yo, por amor, lo he dado todo (...). A veces pienso que he dado demasiado (Pilar, 48 años).

La narración pertenece a una mujer expatriada española que "acompaña" al marido a México y que, por amor, renuncia a su trabajo en España para que su marido pueda aceptar la oferta laboral y vaya acompañado de la familia. Esta narración se enmarca en el estudio centrado en la migración calificada de españoles en México de Mendoza y Ortiz (2006; 2008) y Ortiz y Mendoza (2008; 2010). Con el fin de conocer las experiencias laborales y las prácticas cotidianas y espaciales de españoles en Ciudad de México, se entrevistaron a hombres y a mujeres que trabajaban en empresas transnacionales, instituciones internacionales o en su propia empresa, así como a parejas de expatriados (especialmente esposas). Los resultados muestran como la migración es, para unos, un recurso para maximizar las oportunidades de vida y laborales y, para otras (especialmente mujeres), como una única opción para continuar en pareja y favorecer el cuidado de los hijos/as y las relaciones familiares.

De la misma forma que presentan las geógrafas Yeoh y Khoo (1998) en su estudio con expatriadas británicas en Singapur, nuestro estudio describió que tanto la dificultad de encontrar trabajo a tiempo parcial como la falta de redes familiares de apoyo, obligaban a estas mujeres a dedicarse exclusivamente a sus familias. En este caso, y sin otras opciones, las mujeres aceptan y asumen un papel más tradicional de género que el que ejercían en su país, llegando a lo que Ho (2006) llama la "feminización" de la migración que viene dada por un cambio o redefinición de los papeles y las identidades. En este tipo de migraciones, las esposas de los expatriados se encuentran en desventaja respecto a sus maridos, ya que para ellas es mucho más difícil "reconstruir" sus vidas en un país extranjero (Purkayastha, 2005). Aunque la

2 Todos los nombres propios de las personas entrevistadas han sido anonimizados. 
investigación muestra cómo estas mujeres reconstruyen sus vida cotidianas e intentan aprovechar al máximo su estancia en México, en algunas ocasiones las mujeres llegan a sentir que han "sacrificado" muchos aspectos de su vida en España para viajar con sus maridos y familias. No solo subordinan su propia carrera profesional a favor de la del marido sino que además son las encargadas de facilitar el asentamiento familiar al nuevo país de residencia, reorganizar las tareas dentro del hogar y proveer el amor y el apoyo emocional necesario a todos los miembros de la familia.

Todas las mujeres entrevistadas aseguraban haber aceptado el cambio de residencia no sólo de forma convencida, con ilusión y como una oportunidad para conocer un nuevo país y una nueva cultura, sino sobre todo para "descansar" (según sus propias palabras) de una vida laboral intensa y, en algunos casos, "estresante", para "romper con la rutina” $y$, en el caso de ser madres, para poder dedicarse más al cuidado de sus hijos/as. Afirmaban, pues, que la decisión de vivir en México había sido pactada dentro del hogar y era vivida, como decía una de ellas, como "una apuesta para él pero también como un beneficio para toda la familia" y como "una experiencia que da comodidad y comfort a la familia".

Como señala Cooke (2003), se observa que el "efecto de arrastrar a la esposa" para seguir los pasos de la pareja, se da incluso en situaciones donde el nivel socio-económico de las mujeres es superior al de sus parejas. De esta forma, las migraciones familiares no se explicarían exclusivamente en términos salariales o de promoción laboral, sino que el amor, el cuidado y la responsabilidad jugarían un papel determinante. De todo ello podríamos decir que resulta imposible separar el deseo que tienen los migrantes de mejorar el bienestar económico de su familia de los sentimientos de amor, lealtad y respeto, así como de responsabilidad y cuidado.

Se observaba también como muchas mujeres preferían la opción de migrar a otros tipos de arreglos familiares como la separación temporal de la familia o la movilidad continua del marido por cuestiones laborales (por ejemplo, los casos en los que las mujeres y los hijos/as se quedan en España y los hombres se desplazan periódicamente a trabajar al extranjero). Esta última opción resultaba estresante para el marido y desgastante para el conjunto de miembros de la familia. Así lo corroboraba una entrevistada, en la investigación anteriormente señalada, cuando explicaba que el marido "se pasaba la semana en Bruselas y venía sólo los fines de semana a Madrid" y, de esta forma, la oportunidad de trasladarse a México "la viví como un respiro, en el sentido de que íbamos a estar, finalmente, juntos". De esta forma, las dinámicas familiares, con sus características relacionadas con el cuidado, el apoyo y la obligación hacia sus miembros, resultan fundamentales para entender las diferentes estrategias familiares de migración (Ryan et al., 2009). 
Como ya sabemos la movilidad de las personas altamente cualificadas es una de las características de la globalización. De la misma forma, atraer y conservar trabajadores altamente cualificados son factores clave en las políticas de muchos países del mundo. Sin embargo, en la misma línea de la investigación anterior, y como muestra Aure (2013) para el caso de Noruega, no siempre los migrantes calificados encuentran trabajos adecuados, especialmente cuando éstos no han emigrado por trabajo sino por razones matrimoniales y/o por amor. Esta autora analiza las experiencias de migrantes dependientes, hombres y mujeres altamente cualificados que viven en Noruega, para identificar, desde una perspectiva de género, los factores y los procesos que configuran la exclusión del mercado laboral debido a las responsabilidades familiares, el poco dominio de la lengua o de las características del lugar donde se busca trabajo. En la misma línea, Scott (2006) muestra las diferencias entre hombres y mujeres británicas en París y encuentra que las mujeres que "siguen" a sus parejas se integran mejor que los hombres dependientes, $y$ ve el género como un proceso que perfila resultados distintos para hombres y mujeres dependientes.

La búsqueda de una pareja sentimental fuera de las fronteras del propio país, lo que King (2002) denomina la transnacionalización de la intimidad, es otra de las vertientes donde confluye el amor y la migración. Un ejemplo de esta realidad la presenta Roca (2007) cuando analiza las "migraciones por amor" protagonizadas por mujeres que emprenden la aventura migratoria para formar una familia o una pareja binacional en destino. En su estudio muestra también la importancia de las motivaciones de género como desencadenantes del proceso migratorio y su incorporación a la sociedad de acogida. En otra investigación, Roca et al. (2012) apuntan cómo las mujeres que se casan con un extranjero describen su proyecto migratorio desde los sentimientos y el amor ( $y$ no desde la oportunidad económica) y dejan en manos de sus parejas la inserción en la sociedad de acogida creando una cierta dependencia respecto al entorno social en el que se acomodan.

\section{Amistades en la distancia}

Las emociones y las intimidades de las personas son categorías localmente contextualizadas. Así, pues, la amistad, como otras formas de relaciones sociales, tiene importantes dimensiones geográficas (Bunnell et al., 20II). Las personas mantienen relaciones sociales de amistad tanto si entre ellas la distancia geográfica es muy grande o, por el contrario, si es muy pequeña. La geografía es importante tanto a la hora de hacer, mantener y disolver amistades, como en la configuración del tipo de 
amistades que se construyen en relación al espacio, el lugar y el tiempo. Además, los desplazamientos geográficos alientan a las personas a reconsiderar, reevaluar y repensar el amor y la amistad de forma más consciente.

En la distancia se crean nuevas formas de intimidad. Asílo muestra Walsh (2009) al explorar las nuevas relaciones que se establecen en espacios transnacionales $y$, concetamente, la reproducción y la reconfiguración de las culturas de la intimidad de hombres y mujeres transnacionales británicos en Dubai. A partir de la idea de que la cercanía emocional y física es central para entender la intimidad, la autora conceptualiza aspectos clave de ésta con respecto a las relaciones interpersonales en el marco de la amistad, la familia y la pareja y muestra cómo estas relaciones son constituidas a través de las rutinas cotidianas de la localización del cuerpo, el hogar y el barrio. En las narraciones de las personas entrevistadas surgen sentimientos de decepción, dolor, pérdida y miedo relacionados con la ausencia y la distancia de los amigos, los padres y hermanos. Sin embargo, para otras personas la distancia se percibe como positiva porque ayuda a tejer fuertes lazos de amistad en substitución de la familia o porque ayuda a negociar las culturas convencionales de la intimidad que se sienten opresivas, como sería el caso, por ejemplo, de un entrevistado que dice sentirse a gusto con su relación de pareja a larga distancia porque le permite centrarse en el trabajo y prevenirse de que su relación resulte rutinaria y mundana.

También en su estudio con expatriados británicos en Dubai, Walsh (2006 y 2007) examina las intimidades heterosexuales y concluye que los hombres y mujeres jóvenes a los que entrevista a menudo encuentran una amistad más significativa entre iguales del mismo sexo que en sus parejas. De esta forma, la amistad no substituiría al amor de la pareja, pero se vería como un modelo adicional de intimidad para personas altamente móviles.

\section{Movilidad y nuevas subjetividades}

La movilidad proporciona oportunidades para nuevas formas de subjetividad y emoción (Conradson y McKay, 2007). Las diferencias culturales, sociales, religiosas y de género influyen en los afectos y las emociones y demuestran que tales diferencias son importantes para la creación de subjetividades translocales. Conradson y Latham (2007) analizan la conexión entre la movilidad y la transformación potencial del ser. Concretamente, se centran en las experiencias cotidianas de migrantes cualificados neozelandeses que viven en Londres y observan las posibilidades afectivas asociadas con esta ciudad, así como, las oportunidades que ciertos lugares ofrecen (o se per- 
ciben que ofrecen) para nuevas formas de sentir y ser. De esta forma, estos jóvenes migrantes valoran Londres por su diversidad cultural, sus oportunidades laborales y culturales, por la gran variedad de actividades que hacer en el tiempo libre, la sensación de libertad y el anonimato. Londres ofrece no solo novedad y dinamismo, sino que se presenta como un oportunidad para convertirse en una persona distinta a partir de una serie de desafíos y oportunidades. Para estos autores, la noción de encuentro es central en la concepción del afecto, entendiendo éste como la consecuencia de las interacciones que ocurren entre los cuerpos, los objetos y el lugar.

Por otro lado, la decisión de migrar hacia otro país puede desencadenar diferentes sentimientos (excitación, cólera, miedo, culpabilidad, esperanza, alegría) de aquellos que parten o de aquellos que se dejan atrás. Según Svasek (2010), los procesos emocionales (entendidos como discursos, prácticas y experiencias corporales) dan forma a la movilidad humana. Además, continúa la autora, los "otros" en los encuentros emocionales, no solo son seres humanos sino también animales, paisajes, objetos materiales, imágenes y acontecimientos porque estos también afectan emocionalmente a las personas. En un mundo móvil, los arraigos personales a las personas y a los lugares son múltiples y cambiantes. Así, mientras una bienvenida poco amistosa en el país de llegada puede incrementar los sentimientos de pertenencia al lugar de origen, las buenas experiencias con los miembros de la comunidad local pueden resultar positivas para la construcción de un sentido de pertenencia en el lugar de destino.

Las subjetividades y las emociones son analizadas también por Maehara (20I0) quien analiza las percepciones del hogar y los procesos emocionales que teje un grupo de mujeres japonesas durante los primeros años de migración a Irlanda. La autora explora las relaciones dinámicas que las migrantes crean entre su nuevo país y sus hogares y examina cómo manejan sus experiencias emocionales contradictorias, inconsistentes y ambiguas creadas a través del movimiento a través del tiempo y el espacio. Se observa como el embarazo, la maternidad y el cuidado de los hijos resultan ser aspectos muy significativos en la vida de estas mujeres y proporcionan ejemplos de procesos múltiples e interdependientes en los que emergen las subjetividades y los sentimientos.

¿Cómo interactúan los migrantes emocionalmente con la gente que se encuentran en los países receptores? ¿De qué forma aparecen en los espacios transnacionales nuevas formas de intimidad? ¿Qué papel juegan las emociones de los migrantes en la construcción del sentido de lugar? Estas son algunas de las preguntas a las que las geografías de las emociones y las migraciones van respondiendo y que en líneas generales podemos resumir en tres ideas fundamentales: que las emociones son 
procesos dinámicos constituidas a partir de las experiencias individuales y el lugar; que la migración implica un encuentro con las particularidades de un lugar y construye nuevas dinámicas afectivas, íntimas y emocionales y, finalmente, que existen consonancias y disonancias emocionales que afectan, al migrar, el sentido de lugar.

\section{Un apunte metodológico}

Los resultados presentados en este artículo se enmarcan en un proyecto de investigación que tiene como objetivo analizar las experiencias personales y laborales de hombres y mujeres españolas e italianas con formación universitaria que viven México $^{3}$. Las entrevistas se llevaron a cabo en 2014 y 2015 y se hicieron a hombres y mujeres españolas e italianas residentes en cuatro ciudades mexicanas: Ciudad de México, Guadalajara, Monterrey y Puebla. Para la selección de los informantes se siguieron los siguientes criterios: ser españoles o italianos por nacimiento, llevar viviendo en México al menos un año y haber migrado al país después de concluir los estudios superiores. Se buscó, en la medida de lo posible, un equilibrio en cuanto a la nacionalidad, el sexo y las categorías profesionales y/o laborales de los entrevistados. Para la concertación de entrevistas se recurrió a informantes previamente conocidos y contactos a través de las redes sociales (grupos de Facebook de españoles e italianos en México) y la técnica bola de nieve. Se entrevistaron 129 personas (hombres y mujeres) con el fin de comprender y analizar sus motivaciones para migrar, sus trayectorias laborales y profesionales, su vida cotidiana y sus prácticas espaciales, así como sus expectativas de futuro. Su edad oscila entre los 24 y los 80 años, siendo la media 37,9 años. Y un 87,5\% llegó a México a partir del año 2000.

Este artículo ha tomado básicamente para su análisis a los hombres y a las mujeres que tienen pareja y que viven con ella: las 62 personas que forman parejas mixtas (entre español/a y mexicano/a o italiano/a, mexicano/a), las 25 personas españolas que tienen pareja de su misma nacionalidad y las 8 que la tienen de un tercer país. Esta selección se ha hecho con el fin de comprender qué elementos empujan a las parejas a migrar juntas a México y qué elementos las hacen permanecer en él. Sin

3 Este proyecto de investigación se titula “'Fuga o suma de cerebros?: migración calificada del sur de Europa a las nuevas ciudades emergentes mexicanas", está financiado por el Consejo Nacional de Ciencia y Tecnología (Conacyt). Convocatoria "Proyectos de interés nacional 2013" y dirigido por el doctor Cristóbal Mendoza Pérez del Departamento de Sociología de la Universidad Autónoma Metropolitana-Iztapalapa. 
embargo, en algunas ocasiones, por ejemplo, para entender qué aspectos aparecen como más relevantes a la hora de permanecer en México o querer regresar a España o Italia, se han tenido en cuenta las I29 personas entrevistadas incluyéndose, así también, a las personas que no tienen pareja (tablas I, 2, 3 y 4 ).

$\mathrm{El}$ amor a la pareja y las ganas de continuar juntas, los vínculos emocionales y familiares hacia México, y las mejores oportunidades laborales que ofrecía el país latinoamericano para personas bien formadas durante los años en los que la crisis económica española e italiana afectó con mayor determinación (desde 2008 hasta nuestros días), son algunas de las razones que ayudan a entender porqué parejas formadas en España o Italia, o en otros países, deciden migrar juntas a México. Personas casadas o solteras que cohabitan, parejas heterosexuales la mayoría, pero también homosexuales, divorciadas o alguna viuda, forman el abanico de personas que hemos entrevistado. Las entrevistas se realizaron en las cuatro ciudades estudiadas, duraron entre una hora y hora y media y fueron transcritas en su totalidad.

\section{Cuadro i.}

Perfil de todas las personas entrevistadas

\begin{tabular}{|c|c|}
\hline $\begin{array}{l}\text { Número de personas } \\
\text { entrevistadas }\end{array}$ & $\begin{array}{l}\text { I29: } \\
\text { 8I hombres } \\
48 \text { mujeres }\end{array}$ \\
\hline País de nacimiento & $\begin{array}{l}\text { I07 nacidos en España } \\
22 \text { nacidos en Italia }\end{array}$ \\
\hline Edad & $\begin{array}{l}24 \text { son menores de } 29 \text { años } \\
58 \text { se sitúan entre los } 30 \text { y los } 39 \text { años } \\
34 \text { se sitúan entre los } 40 \text { y los } 49 \text { años } \\
9 \text { se sitúan entre los } 50 \text { y los } 59 \text { años } \\
4 \text { son mayores de } 60 \text { años }\end{array}$ \\
\hline Nivel de estudios & $\begin{array}{l}\text { Todos con estudios superiores (algunos/as licenciatura, otros/ } \\
\text { as licenciatura y maestría y otros/as licenciatura, maestría y } \\
\text { doctorado) }\end{array}$ \\
\hline $\begin{array}{l}\text { Lugar de residencia en } \\
\text { México }\end{array}$ & $\begin{array}{l}\text { 4I Ciudad de México } \\
\text { 3I Monterrey } \\
\text { 3I Guadalajara } \\
26 \text { Puebla }\end{array}$ \\
\hline $\begin{array}{l}\text { Año de llegada a } \\
\text { México }\end{array}$ & $\begin{array}{ll}\text { Antes de 2000: } & 16 \\
\text { Entre 200I y 2005: } & 15\end{array}$ \\
\hline
\end{tabular}




\begin{tabular}{ll}
\hline & $\begin{array}{l}\text { Entre } 2006 \text { y } 201036 \\
\text { Entre 20II y 20I5 } 62\end{array}$ \\
\hline \multirow{3}{*}{ Trabajo en México } & $\begin{array}{l}\text { Son directivos de empresa, técnicos/as en empresa, empresa- } \\
\text { rios/as o trabajadores/as por cuenta propia, académicos/as, } \\
\text { cooperantes o trabajadores/as en el tercer sector }\end{array}$ \\
\hline \multirow{2}{*}{ Estado civil } & $\begin{array}{l}50 \text { están casados/as, 4I son solteros/as, 34 en unión libre, } 2 \\
\text { divorciados/as y 2 viudos/as. }\end{array}$ \\
\hline Hijos/as & 79 sin hijos y 50 con hijos \\
\hline
\end{tabular}

Fuente: Elaboración propia a partir del trabajo de campo realizado entre 2014 y 2015.

\section{Cundro 2.}

Perfil de todas las personas entrevistadas según el origen de su pareja

\begin{tabular}{lccccc}
\hline & $\begin{array}{c}\text { Pareja } \\
\text { mexicana }\end{array}$ & $\begin{array}{c}\text { Pareja } \\
\text { española }\end{array}$ & $\begin{array}{c}\text { Pareja } \\
\text { otro país }\end{array}$ & $\begin{array}{c}\text { Sin } \\
\text { pareja }\end{array}$ & $\begin{array}{c}\text { Total personas } \\
\text { entrevistadas }\end{array}$ \\
\hline DF & I6 & 4 & 5 & I6 & 4 I \\
\hline Guadalajara & I4 & 6 & - & II & $3 \mathrm{I}$ \\
\hline Monterrey & 22 & 3 & 3 & 3 & $3 \mathrm{I}$ \\
\hline Puebla & I0 & I2 & - & 4 & 26 \\
\hline Total & 62 & 25 & 8 & 34 & I29 \\
\hline
\end{tabular}

Fuente: Elaboración propia a partir del trabajo de campo realizado entre 2014 y 2015.

\section{Cuadro 3.}

Perfil de las personas entrevistadas nacidas en España e Italia con parejas mexicanas

\begin{tabular}{lccccccc}
\hline & $\begin{array}{c}\text { Español } \\
\text { con } \\
\text { mexicana }\end{array}$ & $\begin{array}{c}\text { Español } \\
\text { con } \\
\text { mexicano }\end{array}$ & $\begin{array}{c}\text { Italiano } \\
\text { con } \\
\text { mexicana }\end{array}$ & $\begin{array}{c}\text { Italiano } \\
\text { con } \\
\text { mexicano }\end{array}$ & $\begin{array}{c}\text { Española } \\
\text { con } \\
\text { mexicano }\end{array}$ & $\begin{array}{c}\text { Italiana } \\
\text { con } \\
\text { mexicano }\end{array}$ & $\begin{array}{c}\text { Total } \\
\text { parejas } \\
\text { mixtas con } \\
\text { mexicano/a }\end{array}$ \\
\hline DF & 5 & 2 & I & I & 5 & 2 & I6 \\
\hline Guadalajara & IO & - & - & - & 4 & - & I4 \\
\hline Monterrey & I2 & - & 4 & - & 4 & 2 & 22 \\
\hline Puebla & 4 & I & I & - & 4 & - & I0 \\
\hline Total & 3 I & 3 & 6 & I & I7 & 4 & 62 \\
\hline Tuent Ela
\end{tabular}

Fuente: Elaboración propia a partir del trabajo de campo realizado entre 2014 y 2015. 


\section{Cuadro 4.}

Perfil de las personas expatriadas españolas y el origen de sus parejas

\begin{tabular}{lcccc}
\hline & $\begin{array}{c}\text { Pareja } \\
\text { mexicana }\end{array}$ & $\begin{array}{c}\text { Pareja } \\
\text { española }\end{array}$ & $\begin{array}{c}\text { Sin } \\
\text { pareja }\end{array}$ & $\begin{array}{c}\text { Total } \\
\text { Expatriados }\end{array}$ \\
\hline DF & 3 & 2 & - & 5 \\
\hline Guadalajara & - & - & I & I \\
\hline Monterrey & - & I $^{*}$ & - & I \\
\hline Puebla & I & 3 & - & 4 \\
\hline Total & 4 & 6 & I & II \\
\hline
\end{tabular}

Fuente: Elaboración propia a partir del trabajo de campo realizado entre 2014 y 2015.

*Solamente una mujer es expatriada. Llamamos expatriados/as a las personas que van a trabajar al extranjero bajo el mandato de una empresa.

\section{Evidencias empíricas de migraciones por amor: "Fue un poco todo ... el amor lo aceleró"}

Un $23 \%$ de las personas entrevistadas en nuestro estudio (de un total de I29 personas) dicen que la principal motivación para migrar a México fue por amor. "Me enamoré", "conocí a un chico", “yo la acompañé", "lo abandoné todo por él”, son algunas de las expresiones que utilizan algunas personas cuando se refieren a sus muy variadas experiencias de migración hacia México. La cita que da título a este apartado es de Mariana, una mujer de 28 años que en 2013 decidió regresar a Chiapas desde España porque en su primer viaje a México se enamoró de una mujer mexicana. Aunque, como ella dice "el amor acabó y además muy malamente", Mariana continúa viviendo y trabajando en este país.

Las ganas de regresar al país de origen de su pareja fue lo que empujó al siguiente entrevistado a trasladarse a México. Al principio la acompañó sin mucho interés por asentarse en el país o encontrar trabajo, pero más tarde, y precisamente en el momento en el que su novia se quedó embarazada, decidieron casarse y vivir en la ciudad donde nació su esposa:

No tenía previsto quedarme a vivir aquí, pero llevaba dos años de relación con mi actual esposa, y ella quería regresar a su país y yo la acompañé con mucha curiosidad por el país. Luego, tampoco con una expectativa de establecer aquí mi residencia... 
Lo que pasa es que después vino nuestra hija, nos quedamos embarazados, y de momento nos establecimos aquí en Monterrey (Pere, 40 años, llegó en 2010).

Otra experiencia es la que describen Lorenzo e Isidro que conocieron a sus parejas mexicanas respectivas a través de las redes sociales. Lorenzo vino a México por amor después de convivir con su novio durante unas vacaciones en España e Isidro migró después de algunos años de relación a distancia y una vez casados en España:

Conocí a mi pareja (...). Él regresó a México, vivía aquí y a los cinco meses ya vine yo (...). Fue de vacaciones en el verano, quedamos de vernos, nos conocimos, estuvimos viéndonos bastante mes y medio que él estuvo. Luego seguimos hablando. Yo, la verdad, quizá necesitaba mucho salir de mi pueblo (...). Yo tenía veinticuatro cuando llegué aquí (...). Lo conocí en abril por internet, físicamente en julio, y yo en febrero ya estaba aquí (Lorenzo, 36 años, llegó en 2002).

Por matrimonio. Yo conocí a mi mujer a través de las redes sociales. Pero yo nunca me imaginé que me fuera a casar con una mexicana. Entonces me vine a México. Pero empezamos a hablar, y era todos los días, todos los días, muchas horas invertidas hablando. Y pues estuvimos como tres años de novios, declarados, más tiempo anterior hablando. Yo había venido varias veces a verla. Ella también fue un par de veces a España. Entonces decidimos casarnos. Y bueno, pues pensé que lo mejor sería venir a México, quedarnos aquí a vivir. Por eso fue. No fue por buscar trabajo ni nada de eso. Fue por amor (Isidro, 38 años, llegó en 2008).

\section{Dos pájaros de un tiro: "vine por amor y por trabajo"}

Digamos que vine por amor y por trabajo [...]. [Ella] Fue la razón principal porque ella es de acá, porque al no encontrarnos solución allá, porque a ella también le gusta allá, pues dijimos venimos acá. Sí, pensamos en ir, pero que primero al D.F porque hay más oferta laboral, pero ya que teníamos una casa aquí [Guadalajara] pues primero intentarlo aquí, y aquí nos quedamos" (Ernest, 26 años, llegó en 2012).

Como Ernest, los hombres y las mujeres españolas e italianas con parejas mexicanas migran a México por amor siguiendo a sus parejas, pero también, muchas veces, animados por una situación laboral precaria, insegura e inestable en su país 
de origen. Un 26\% de las personas entrevistadas asegura que migró a México por amor y trabajo.

Estas parejas mixtas formadas en España e Italia, principalmente, pero también en otros países e incluso, como hemos visto, a través de las redes sociales, escogen México porque el miembro mexicano de la pareja desea regresar a su país de origen, ya sea por cuestiones afectivas vinculadas a la familia, ya sea porque considera que en su país tanto él/ella como su pareja tendrán más y mejores oportunidades laborales. Sería el caso de Juan Carlos que se casó en España con su novio mexicano y, al estar desempleado en España, decidió ir a México. Se "lanzó a la piscina", comenta, y vino "por él":

Pues realmente vine por mi pareja. México no estaba en mis planes, nunca, porque pensaba que era un país inseguro, peligroso, con pocas posibilidades laborales, y realmente me lancé a la piscina y fue por mi pareja (...). Es verdad que yo no tenía nada, ni empleo, ni nada, pero me vine aquí por él, y acepté a casarme por estar aquí, y poder vivir con él (Juan Carlos, 24 años, llegó en 2013).

Pero no siempre la falta de empleo, la precariedad o la temporalidad laboral resulta ser un motivo más, además del amor, a la hora de apostar por la migración. En algunas ocasiones se observa como a pesar de que los españoles/as tienen un buen trabajo remunerado en su país priorizan la situación laboral de la pareja mexicana. Es el caso de David, Dora y Marisol. David, que está separado en el momento de la entrevista, decidió venir a México porque su esposo, recién doctorado en España, debía regresar a México para trabajar tal y como le exigía la beca otorgada por el gobierno mexicano. A David le costó mucho decidirse porque tenía una plaza de funcionario en una institución pública madrileña; pero, ante la insistencia de su esposo, optó por la migración:

Me casé en España hace siete años. Nos trasladamos para acá por el trabajo de él y nada, llegamos y estuvimos viviendo tres años en Mérida y luego al final decidimos separarnos y él sigue allí y yo me vine para el D.F. (...). Él llevaba dos años con "vámonos, vámonos, vámonos" (...). Yo era fijo de [institución española], entonces a mí me hacía polvo. Por eso me costó tanto el decidirme venir (...) fue muy complicado, fue lo peor. Tardé dos años en decidirme (David, 34 años, llegó en 2009).

También Dora, soltera en el momento de la entrevista, tenía un excelente trabajo en España que le satisfacía económicamente, le permitía viajar y vivir temporadas 
largas en distintos países del mundo. En España conoció a su novio mexicano y decidió venir definitivamente a México después de pasar unas vacaciones juntos en este país. Comenta que lo abandonó todo por amor y que a pesar de que esta relación sentimental terminó, continúa viviendo en México porque está contenta con su trabajo y sobre todo porque considera que hay pocas perspectivas laborales en España: "[V]ine porque conocí a una persona mexicana y bueno pues digamos lo abandoné todo y emigré a México y no tuve suerte en el amor pero sí tuve suerte en lo laboral" (Dora, 49 años, llegó en 20II).

De la misma forma, cuando a Marisol se le pregunta por sus motivaciones para venir a México responde también que fue para que su esposo, que estaba en Barcelona sin trabajo, pudiese encontrar más fácilmente un trabajo “de lo suyo" en México. Ella tenía trabajo, pero dio prioridad a los deseos y necesidades de su pareja:

Yo tenía un trabajo y lo dejé para venir acá. Cuando estábamos en Emiratos, ya visionamos venir acá y mientras tanto yo encontré trabajo en Barcelona. Como ya habíamos encarrilado esta idea, pues ya al final la dejé y vinimos para acá. Y una cosa secundaria fue que mi esposo tenía a su madre enferma y lo principal era el trabajo de mi esposo, porque en Barcelona no podía trabajar en lo suyo y aquí sí (...). Fueron motivos de mi esposo, no míos personales, sí, sí (Marisol, 4I años, llegó en 20II).

Para algunos de los entrevistados, México no ha sido la primera experiencia migratoria. Pedro vivió unos años en el Reino Unido antes de migrar a México. Está casado con una mexicana y tiene dos hijos. Se conocieron en España, pero en 200 fueron a vivir a México y allí estuvieron dos años hasta que decidieron ir al Reino Unido donde él obtuvo el grado de doctor y ella estudió una maestría. Su intención era establecerse un par de años en el extranjero para estudiar, pero se quedaron ocho años ya que él obtuvo un puesto en una universidad y ella un cargo de dirección en un museo. Dejaron el Reino Unido porque, ya con dos hijos, les pareció que México les podía ofrecer una mayor calidad de vida y porque a él, con su trayectoria académica en el extranjero, México, más que España, le ofrecía mejores oportunidades de promoción laboral. En México, Pedro comenta que mientras él ha crecido profesionalmente, su esposa ha sufrido una cierta descualificación laboral al no haber conseguido todavía un trabajo con una categoría similar al del Reino Unido:

Cuando vinimos del Reino Unido, yo tenía más claro de venir a México que ella, porque la calidad de vida era mejor en México, y porque en la academia podía irme 
bien (...). A mi esposa, por el lado de los niños, sí le pareció bien cambiarnos. Pero, por el lado de su trabajo, ella ha perdido más que yo. Ahí las instituciones culturales son muy buenas y hay muchas prácticas y actividades sobre el tema de educación y cultura. Es un balance de prioridades. Nos pareció que era un momento bueno para cambiar (Pedro, 42 años, llegó en 2011).

Frente a una situación laboral inestable e incierta, en la que no se ven muchas expectativas de futuro en España, Alejandro y Marcos, los dos casados con mujeres mexicanas, decidieron migrar a México porque sabían que las ofertas laborales eran mayores y porque valoraron muy positivamente que la red familiar de sus esposas podía ayudarles en la conciliación del trabajo y la familia. Alejandro y su esposa dudaron entre China y México, pero al final, apelando a su "responsabilidad como padres" $y$ "al tener una familia en crecimiento", según comenta, apostaron por el país de la esposa para que hubiese una red familiar que los arropase durante el proceso de integración en el nuevo país y más tarde en el cuidado de sus hijos/as:

Fue por una situación económica complicada en España. A pesar de no tenerme en la raya de la desesperación, sí que estaba viendo cómo se estaba constriñendo mi futuro, a nivel económico. Al tener una familia en crecimiento, mi señora y yo hicimos una gráfica de expectativas y realidades (...). Mi señora es mexicana. Es cierto que también tuvimos otros puntos para emigrar que no era México; teníamos Shanghái, porque yo ahí tenía unas posibilidades de proyecto. Pero al final decidimos venir a México por temas económicos, como he dicho, y básicamente por temas de arraigo familiares; ella es regia, de Monterrey. Pensamos que sería mucho más fácil comenzar de cero en un sitio donde no partes de cero, a nivel de contactos. [...]. Y con mi señora decidimos hacer el cambio (...). Desestimamos otras posibilidades, como ir a China (...). Y cuando se tiene un hijo, tienes que hacer la apuesta más sobre seguro. Hay que ser responsable (Alejandro, 40 años, llegó en 2013).

Con otras palabras, pero en la misma línea, Marcos expresa su experiencia de la siguiente forma:

En 2006 conozco a mi actual esposa, y en 2008 nos casamos y viene la crisis y todo se complica. Entonces, del 2008 a 2012, conseguimos más o menos vivir bien, con algunos apuros y todo. Pero en 2012 decidimos venirnos para acá (...). Los dos teníamos trabajo y decidimos “Por qué no nos vamos ahora que los dos tenemos trabajo, en lugar de esperarnos a que nuestra situación sea más complicada? (...). 
Está tu familia allí. En México no es que las cosas están de lo mejor, pero parece que hay más oportunidades (Marcos, 33 años, llegó en 20I2).

Se observa que cuando la pareja es mixta entre español/a y mexicano/a se elige el país en el que un miembro de la pareja, generalmente el hombre, pueda desarrollarse más profesionalmente, aunque a veces tenga que sacrificarse el trabajo de uno de ellos, generalmente el de la mujer. Ricardo, por ejemplo, llegó como expatriado a México, pero al cabo de seis meses conoció a la que sería su esposa y junto a ella regresó a España donde estuvieron tres años. En 2013 decidieron regresar nuevamente a México gracias a una muy buena oportunidad laboral para él y a las ganas de regresar a su país de origen por parte de su esposa. Su matrimonio con una mexicana le otorgó ventajas legales que le facilitaron los trámites de residencia y laborales y le aseguró una más rápida adaptación al país, aspectos que valora muy positivamente:

Conozco el país, mi mujer es mexicana y el puesto es idóneo para mí y para mi perfil. Mi esposa es la piedra angular de mi carrera profesional, ella es mi musa, mi empuje, mi todo; es una pieza vital en todo esto. Influyó en cómo hice las compras en 2010, cómo negocié con los proveedores... No es lo mismo que un español venga aquí, no conozca México y se ponga a negociar con los proveedores, que un español que viene, conoce a una mexicana, se adapte a la comida mexicana, a la calle mexicana... porque yo me muevo por todo México, no tengo ningún problema en meterme en cualquier sitio. No le tengo miedo a México y eso es gracias a ella (Ricardo, 37 años, llegó en 2013).

En algunas ocasiones, entre los miembros de parejas mixtas entrevistadas, el país de residencia se elige en función de las oportunidades laborales de uno de los dos miembros. En el caso de Llorenç, de 53 años, él y su pareja mexicana eligieron instalarse en México porque la trayectoria académica de su esposa, que en el momento de la entrevista trabajaba en una universidad de Monterrey, podía desarrollarse mejor en su país de origen que en España debido a las dificultades para conseguir trabajo en las universidades españolas. En su caso, comenta, su actividad laboral, relacionada con el marqueting e internet, puede desarrollarse sin mayores dificultades en un país o en el otro.

Por otro lado, mantener a la familia unida y moverse con ella a otro país es para muchos expatriados fundamental para acceder a la expatriación que les ofrecen las empresas para las que trabajan en España. Los hombres expatriados entrevistados aseguran que a pesar de la satisfacción que les da su trabajo, el ascenso en la 
categoría profesional, las mayores responsabilidades laborales y el aumento en los ingresos, no hubiesen aceptado su traslado a México si sus esposas (y sus hijos/as) no les hubiesen "seguido". Sería el caso de Juan, casado con una mujer española (con un trabajo remunerado acorde con su cualificación en España pero sin trabajo en México) y con una hija de I2 años:

"Ellas se han adaptado súper bien y yo no hubiera venido sin mi familia" (Juan, 47 años, llegó en 2012). Como puede observarse, y como se halló en investigaciones anteriores (Ortiz y Mendoza, 2008 y 20IO) el número de hombres expatriados entrevistados supera al número de mujeres, io y I, respectivamente (ver tabla 4). Esto mostraría que dentro de las parejas se "arrastra" mucho más a las esposas, aunque éstas tengan un buen trabajo en España (o similar al del marido) y mucho menos a los esposos, cuyo trabajo, generalmente de mayor categoría (o similar al de sus esposas) se privilegia.

\section{Relaciones sentimentales a distancia y reencuentros en México}

Las relaciones de pareja a distancia, tanto mixtas como de españoles, terminan provocando que uno de los dos miembros de la pareja se traslade a vivir al país de la pareja o a uno nuevo con el fin de estar juntos. Después de conocerse y empezar su relación, Manuel y su pareja mexicana estuvieron un año separados, él en España y ella en México, hasta que al final valorando el trabajo y la estabilidad laboral de cada uno, Manuel dio el paso definitivo al otro lado del Atlántico para estar juntos:

Conocí a mi pareja (...) y la relación siguió funcionando por internet, teléfono... Pensamos si ella se iba para Madrid o yo me venía para acá. Y como estaban las cosas, y como [ella] también tiene una relación más consolidada profesional aquí, dijimos "pues voy para alla’". Y hasta hoy, nueve años (Manuel, 38 años, llegó en 2005).

El amor a distancia se mantiene un tiempo que puede ser más o menos largo dependiendo de las circunstancias, pero al final si la pareja desea continuar su relación se decide migrar a un país o al otro. En un primer momento, el ir y venir por trabajo, de España a México, y tener la familia en el país de origen, es una estrategia que siguen algunos entrevistados para continuar casados o en pareja y mantener un buen trabajo. Sería el caso de Juan Manuel que llevaba alrededor de 20 años "yendo y viniendo por negocios a México". En 2008, cuando empezó la crisis económica en España, decidió abrir una oficina en Monterrey y vivía medio año en España y 
medio en México separado de su mujer y sus hijos. Cuando vio que los resultados económicos en México superaban a los de España decidió establecerse con su familia en México:

En 2007 y 2008 empezó la fuerte crisis, y decidí venirme para acá. Mi mujer y mis hijos se quedaron. De hecho, yo venía 6 meses y me iba. Pero finalmente las cosas se iban dando peor allí y aquí mejor. Llegó un momento, al año y tres meses, en que decidimos que mi mujer, mis hijos y mi perro nos viniéramos para acá (Juan Manuel, 53 años, llegó en 2008).

La elección de la ciudad de residencia dentro de México se da principalmente también por los vínculos emocionales y familiares del miembro mexicano de la pareja. Vivir en Ciudad de México, Guadalajara, Monterrey o Puebla no depende tanto del trabajo sino más bien del hecho de que sea la ciudad de origen de la pareja. Trini, que comenta que vino a México "por amor", reside en Monterrey porque su pareja es regia:

Si yo volvía a España era seguro que cortábamos y si me regresaba a México era más fácil que estuviéramos juntos, entonces decidí regresarme a México y yo busqué trabajo aquí, por amor todo. [Vinimos a Monterrey] porque la familia de mi novio vive aquí, y ellos se criaron aquí (Trini, 3I años, llegó en 2009).

De la misma forma que el estudio de Maehara (2010) sobre mujeres japonesas migradas a Irlanda, nuestras entrevistadas muestran como la convivencia con el marido, los hijos/as, los suegros/as, la relación con sus vecinos/as y las nuevas amistades les afectan emocionalmente y les hacen cambiar sus prioridades, preocupaciones, expectativas, objetivos, planes, hasta el punto de formarse y reformarse las percepciones del 'hogar'.

En otras ocasiones, del noviazgo a distancia se pasa al matrimonio y residencia en México. Es el caso de Paco que vivía entre México y España hasta que su novia española, trabajadora social y actualmente con una excedencia laboral, le dijo que no aguantaba más la separación y decidieron casarse. Actualmente, viven en México porque en la empresa de Pedro le pidieron instalarse definitivamente en este país. Comenta que la crianza y la escolarización de su hijo les ha ampliado su vida social y les ha dado la posibilidad de relacionarse con otros padres y madres y tejer una nueva red de amistades: 
Profesionalmente te desgastas mucho y eso afecta a tu vida personal. Llegó un momento en que mi mujer me dijo "mira, vamos a tomar una decisión, o nos vamos a México o ya te quedas en España y no vas a ningún sitio, porque no tiene sentido que estés así" (...). Aquí al principio no teníamos al niño, que te abre mucho tu vida social, las madres del colegio, la guardería, ese tipo de cosas. Al principio un poco complicado, porque tu relación básicamente se basa en la gente que conoces, con la que estás veinticuatro horas, que es la gente de su trabajo, con lo cual, si no trabajas, al final, es más complicado. Entonces, bueno, las cosas no son fáciles, venir aquí y dejar todo allí, tu familia, amigos, tu estabilidad, tu zona de confort, digamos (Paco, 34 años, llegó en 2010).

\section{Permanecer o regresar: tensiones entre lo familiar y lo laboral}

De la misma forma en la que lo planetan Domínguez-Mujica y Avila-Tàpies (2013) en su trabajo sobre migrantes japoneses en las Palmas de Gran Canaria en España, nuestros testimonios, como veremos a continuación, muestran que el sentido de pertenencia a México se configura en base a la reconceptualización del lugar, la cultura, las relaciones interpersonales y el contacto con la sociedad de acogida. De esta forma, dependiendo de sus experiencias vitales en México y de sus expectativas laborales, del éxito laboral pero también de sus parejas y de las redes sociales y familiares que hayan tejido en el país, las personas entrevistadas se encuentran más o menos a gusto en México y tienen más o menos ganas de regresar o quedarse. En el ámbito personal, tener pareja y vivir con ella o con amigos/as, tener amigos y amigas y sentirse bien aceptado en la familia de la pareja son los aspectos que más a menudo aparecen para mostrar sus ganas de continuar viviendo en México. En el ámbito profesional, los aspectos que más pesan en la balanza de regresar o permanecer en México son los relacionados con la autoestima, el sentirse bien tratados y valorados, el tener un trabajo adecuado a sus estudios y nivel de formación y el tener posibilidades de promoción.

También se observa que el hecho de que muchos de ellos migrasen a México por trabajo y la percepción todavía negativa de las oportunidades laborales en España, les anima a continuar en México. Más aún, algunos de ellos, especialmente los que han vivido en más de un país fuera del suyo y no tienen hijos, estarían dispuestos a vivir en otro país del mundo si esto les supusiese una mejora laboral. Contrariamente, y especialmente entre los entrevistados más jóvenes, la añoranza de la familia (padres, hermanos, sobrinos...) y las amistades, a pesar de la comunicación 
asidua que tienen a través de la telefonía digital e internet, así como en algún caso la remuneración baja que reciben en el trabajo, son aspectos que les pesan y les hacen desear un regreso inmediato.

En otros casos, cuando la pareja española permanece en España, las ganas de regresar aumentan. Sería el caso de Judit quien a pesar de que en España no trabajaba en nada relacionado con sus estudios ni en nada que la motivara personalmente y en México sí, tiene intención de volver a España para regresar junto a su pareja. Otros se ven regresando a España al cabo de unos años, cuando se hayan desarrollado profesionalmente y puedan regresar certificando una trayectoria laboral exitosa.

También temporal se imagina Felisa su estancia en México, aunque su estancia se va alargando y ya lleve seis años en el país. Se siente a gusto en el país y está contenta con su trabajo, pero no se imagina asentándose definitivamente en México y continúa sintiendo la necesidad de estar más cerca de los suyos, su familia y sus amigos, una añoranza que no ha dejado nunca de sentir. El hecho de sentirse estancada en su trabajo y pensar que el mismo trabajo que realiza lo podría estar desarrollando en su ciudad natal le provoca desazón y desasosiego:

Al principio, me gustaba mucho y yo luchaba por integrarme. Me quería sentir cómoda aquí, estando tan lejos de mi casa (...). Me gustaría hacer ese trabajo en mi ciudad, cerca de donde está mi casa, de donde nací, donde están todos mis amigos, mi familia. Que no tenga que ahorrar tanto, ni cruzar el mundo para verlos (Felisa, 28 años, llegó en 2009).

También las mujeres españolas que deciden emigrar para vivir en el país de su pareja manifiestan, al igual que las mujeres españolas entrevistadas por Roca (20I6), un deseo de regresar algún día a España o al menos a dejar la puerta abierta a este retorno. Paola comenta que ya hace tiempo hubiese regresado a Italia si no fuera porque en México vive su pareja mexicana:

Yo regresaría a Italia con mucho gusto. Es decir, a mí nunca me ha gustado vivir aquí y luego me acostumbré, y luego te encariñas, y luego cuando pasan los años ya no te vas y estas cosas, y bueno ahora tengo mi pareja y así. [...]. [que tu pareja sea mexicano, ¿es uno de los motivos por los cuales estás acá?] Sí, actualmente sí. Yo creo que, si estuviera sola, igual ya me hubiera ido (Paola, 33 años, llegó en 20I2).

Por lo que se refiere a las personas entrevistadas más jóvenes, sin descendencia, se observa que cuando se llega a una cierta categoría y éxito profesional, consecución 
difícil en España e Italia para los menores de 30 años, resulta una razón suficiente para quedarse en México. Sin embargo, cuando se imaginan con descendencia las cosas cambian y piensan en regresar para que sus hijos/as puedan disfrutar de una mejor calidad de vida en su país de origen:

Pero con la posibilidad de regresar a Italia más seguido. No tanto porque extrañe mucho, sino porque no quiero que mis hijos pierdan el contacto con sus raíces y porque quiero que vean y conozcan otras cosas que aquí no están presentes. Allá podrán salir a la calle, divertirse, ir al campo a jugar, ir con la bicicleta y hacer muchas cosas, conocer la cultura y conocer a su familia (Davide, 3I años, llegó en 2009).

Pero no todos opinan lo mismo. Juliano, no se imagina regresando a Italia porque comenta que "el país no mejora". Si viese que la situación mejora, regresaría "porque allá están las calles donde he crecido y viví, y mi familia, pero, tengo dudas de que la situación mejore en un tiempo razonable" (Juliano, 29 años, llegó en 20I2).

Otro caso similar sería el de Javier y el de su esposa española que, a pesar de estar muy satisfechos con sus respectivos trabajos, son conscientes de que cuando tengan hijos tendrán que decidir "dónde los quieres criar [porque] aquí no hay abuelos, y es una decisión muy difícil". Javier reflexiona sobre la educación y la escolarización de sus hijos y las diferencias que se dan en un contexto y en otro. En España, comenta, escolarizaría a su hijo en una escuela pública, de barrio, mientras que en México, como ve hacer a todos sus amigos españoles, lo llevaría a regañadientes a un colegio privado donde los valores que aprendería, según su percepción, serían otros:

Hay valores que no me gustaría que tuviese. El egoísmo del individuo, el clasismo. Aquí llevaría a mi hijo al mejor colegio, lo cual le haría estúpido. Yo he ido a colegio público de barrio toda la vida. Y siempre le he dicho a mi mujer, que ella ha ido al colegio privado, de monjas, que yo no la llevaría al colegio de monjas. Entonces hay ciertos valores y ciertas cosas que no me gustarían. Si las hago, pues las tendré que hacer. No me queda otra (Javier, 30 años, llegó en 20II).

Una experiencia distinta es la que tiene Victoria, ingeniera de formación, divorciada y con dos hijos, de Io y I3 años. Valora muy positivamente la escuela de sus hijos porque es una escuela internacional que sería imposible costearla en España, pero en México la empresa de su exmarido, un expatriado, la paga. A pesar de no tener un trabajo estable, Victoria se siente una mujer "privilegiada" por estar en México y no tiene ninguna intención de regresar a Barcelona: 
[Mis hijos] están encantados. De hecho estos días está mi madre conmigo y me está machacando y machacando y regresa, regresa, regresa, porque aquí no tienes trabajo... y yo no le digo nada pero pienso 'ni loca, ni loca, ni loca regreso' (...). A nivel económico todavía no me salgo muy bien. Pero me da igual, me da igual. (...) El cole termina a las dos de la tarde o a las tres. Ahora, por ejemplo, mi hijo pequeño a las tres, cuando sale, hace mecanografía en el mismo cole. Llega a casa a comer y a las cuatro y media ya tiene básquet hasta las seis y media... pobrecitos, se pasan la vida fuera. Y más tarde tarea y a dormir. Durante la semana entre la escuela y extraescolares están muy fuera. Y los fines de semana somos socios del parque España que es club de aquí (Victoria, 48 años, llegó en 2012).

Para Juan también es una prioridad que su familia se sienta a gusto en México y esta satisfacción es la que le motiva a continuar en el país. Considera importante mantener buenas relaciones con las familias del colegio de su hija y contar con una buena red de amistades:

Estamos aquí, porque estamos de acuerdo. Cuando nos venimos aquí, a mi mujer también le interesaba mucho el conocer otras culturas, otras formas de pensar y de ver la vida (...). Si yo, en su momento, hubiera visto que mi familia no está a gusto, me habría regresado a España. [Mis hijas están] perfectamente (...). Es importante también tener buena relación con los padres de las compañeras de tu hija. Pero, sobre todo del punto de vista, no buscar una familia, porque la familia no la puedes substituir, pero sí buscar gente cercana a ti con la que puedas contar en todo momento (Juan, 4I años, llegó en 2008).

\section{Reflexiones finales}

La decisión de migrar desencadena sentimientos encontrados y diversos por parte de aquellas personas que deciden ir a vivir a otro país: dudas frente al cambio, miedo a equivocarse, tristeza y añoranza, reacomodo emocional, alegría al encontrar trabajo, felicidad por la creación de una nueva familia y satisfacción por unas nuevas amistades.

De las 129 personas entrevistadas, un 23\% de las personas entrevistadas señaló que su principal motivación para migrar fue por amor. Se trata de parejas que iniciaron su relación en España, en Italia o en otro país (o incluso a través de las redes sociales por internet) y que deciden emprender una migración al país de su pareja, 
México. Siguen a la pareja por amor y para estar junto a ella, a pesar de tener un buen trabajo en Europa o no haberse planteado hasta el momento la posibilidad de migrar. En algunas ocasiones la pareja vive durante una temporada separada manteniendo una relación a distancia hasta que una de las partes decide migrar al país de la pareja. Otro porcentaje elevado, $26 \%$, apunta que, junto al amor, el trabajo y especialmente la falta de éste en España o Italia debido a la crisis económica de 2008 , resulta un aspecto decisivo para migrar. El resto de las personas entrevistadas no nombran el "amor" entre sus razones para migrar; de esta forma, un $39 \%$ señala que migró por trabajo, un $5 \%$ por estudios, un $5 \%$ por un espíritu aventurero y un $2 \%$ por tener a su familia de origen. Esta clasificación es solo un intento de sistematizar los resultados, ya que en realidad no existe un único motivo para migrar sino que pueden ser múltiples y tienen que ver con la complejidad humana y social.

Un aspecto relevante desde un enfoque de género, al igual que muestra Roca (2016), es la constatación de que las parejas toman la decisión de migrar a México más en función del proyecto laboral de los hombres (tanto si son mexicanos como españoles o italianos) que del proyecto de sus esposas (o novias). A menudo éstas, aun teniendo un buen trabajo remunerado en España (en menor medida en Italia), abandonan sus trabajos para que sus esposos (o novios) tengan mejores oportunidades para encontrar un trabajo acorde a sus cualificaciones académicas en México.

Junto el amor y el trabajo, la red familiar (padres y hermanos/as) de las mujeres mexicanas, especialmente, resulta ser un motivo de peso para decidir instalarse en México. No sólo el vínculo emocional con la familia sino también el apoyo que ésta puede proporcionar en el cuidado de los hijos/as aparece como un aspecto a tener en cuenta cuando la pareja valora en qué país asentarse. Cuando se tienen hijos/as estar lejos de los abuelos/as o hermanos/as se ve como una desventaja y, de esta forma, la red familiar se revaloriza ya que puede ayudar no sólo a cuidar a los nietos/as mientras los padres trabajan, sino que también puede proporcionar una estabilidad emocional hasta el punto de fijar la residencia cerca de los abuelos/as. También los expatriados (todos hombres) comentan que, solos, sin su pareja o sus hijos/as, no se hubieran trasladado a México porque sin la presencia de su familia su proyecto profesional hubiese carecido de sentido.

Por tanto, la crianza y la educación de los hijos/as es uno de los elementos que más señalan las personas entrevistadas cómo significativos a la hora de decidir si quedarse o regresar a Europa. Entorno a este tema surgen opiniones muy dispares. Así, mientras que unos abogan por regresar y hacen referencia a la calidad de vida de sus lugares de origen o a la calidad de la educación pública en Europa, otros, especialmente los expatriados, señalan que las escuelas (privadas) a las que van sus 
hijos son de gran calidad y una oportunidad para el ascenso social. Una vez instalados en México, la satisfacción laboral y su integración en la sociedad mexicana son aspectos relevantes para explicar la permanencia en el país de aquellas personas que migraron a México por amor ( $y$ continúan junto a sus parejas iniciales), pero sobre todo para explicar porqué permanecen aquellas que terminaron su relación con la pareja por la que decidieron venir a México.

Finalmente, y como resumen de nuestros resultados, podemos asegurar que las emociones están constituidas dinámicamente a partir de las experiencias individuales en un lugar determinado y que existen consonancias y disonancias emocionales que afectan a las experiencias migratorias, al sentido de pertenencia y al bienestar en el lugar.

\section{Bibliografía}

Ahmed, Sara (200I), "Communities that feel: intensity, difference and attachment", en: Anu Kuoivunen y Susanna Paasonen (eds.) Affective encounters, Turku: School of Arts, Literature and Music Publications. University of Turku, pp. IO-25.

Aure, Marit (2013), "Highly skilled dependent migrants entering the labour market: gender and place in skill transfer", Geoforum, vol. 45, pp. 275284. doi:10.1016/j.geoforum.2012.11.015.

Boccagni, Paolo y Loretta Baldassar (2015), "Emotions on the move: Mapping the emergent field of emotion and migration", Emotion, Space and Society, vol. 16, pp. 73-80. doi:10.1016/j.emospa.2015.06.009.

Boiger, Michael y Batja Mesquita (2012), "The construction of emotion in interactions, relationships and cultures", Emotion Review, 4(3), pp. 22I-229. doi: I0.1177/1754073912439765.

Bunnell, Tim, Sallie Yea, Linda Peake, Tracey Skelton y Monica Smith (20II), "Geographies of friendships", Progress in Human Geography, 36(4), pp. 490-507. doi:10.1177/0309132511426606.

Conradson, David y Alan Latham (2007),"The affective possibilities of London: Antipodean transnationals and the overseas experience", Mobilities, 2(2), pp. 23I-254. doi:10.1080/17450100701381573.

Conradson, David y Deirdre McKay (2007), "Translocal subjectivities: mobility, connection, emotion", Mobilities, 2(2), pp. 167-I74. doi:10.1080/17450100701381524. 
Domínguez-Mújica, Josefina y Rosalía Ávila-Tàpies (2013), "The in-between lives of Japanese immigrants in Las Palmas de Gran Canaria, Spain", Gender, Place and Culture, 20(7), pp. 896-913 doi:10.1080/09663 $69 \mathrm{X} .2012 .737767$.

Gallo, Ester (2015), "The irony of kinship migration and the control of emotions among Malayalis", Emotion, Space and Society, vol. 16, pp. I08-II5. doi:I0.10I6/j.emospa.20I4,I2.00I.

Giménez Bartlett, Alicia (2006), Días de amor y engaños, Barcelona, Planeta.

Huang, Shirlena y Brenda S.A. Yeoh (2007), "Emotional labour and transnational domestic work: the moving geographies of 'maid abuse' in Singapore", Mobilities, 2(2), pp. 195-217. doi:10.1080/17450100701381557.

King, Russell (2002), "Towards a New Map of European Migration”, International Journal of Population Geography, vol. 8, pp. 89-I06. doi:I0.I002/ ijpg.246.

Maehara, Naoko (2010), "Emotional ambiguity: japanese migrant women in mixed families and their life transition", Journal of Ethnic and Migration Studies, 36(6), pp. 953-966. doi:10.1080/13691831003643371.

Mendoza, Cristóbal y Anna Ortiz (2006),"Hacer las Américas: Migrantes espanoles de alta calificación en la ciudad de México", Documents d’Anàlisi Geogràfica, vol. 47, pp. 93-II4.

Mendoza, Cristóbal y Anna Ortiz (2008),"Espacio vivido y prácticas cotidianas de españoles/as en la Ciudad de México", Iztapalapa. Revista de Ciencias Sociales y Humanidades, vol. 64-65, pp. 165-186.

Mendoza, Cristóbal, Barbara Staniscia y Anna Ortiz (2016), "Migración y movilidad de las personas calificadas: nuevos enfoques teóricos, territorios y actores", Biblio 3 W. Revista bibliográfica de geografía y ciencias sociales, XXI(III6) [en línea].

Ortiz, Anna y Cristóbal Mendoza (2008), "Vivir (en) la ciudad de México: espacio vivido e imaginarios espaciales de un grupo de migrantes de alta calificación", Latin American Research Review, 43(I), pp. II3-I38. doi:10.1353/lar.2008.0016.

Ortiz, Anna y Cristóbal Mendoza (2010),"Reconstruint identitats i noves quotidianitats. El cas d'un grup de dones espanyoles a Ciutat de Mèxic", Papers: Revista de Sociologia, 95(2), pp. 30I-320.

Raghuram, Parvati (2004), "The difference that skills make: gender, family migration strategies and regulated labour markets", Journal of Ethnic and Migration Studies, 30(2), pp. 303-321. doi:10.1080/1369183042000200713. 
Roca Girona, Jordi (2007),"Migrantes por amor: La búsqueda y formación de parejas transnacionales", Aibr. Revista de Antropología Iberoamericana, 3(2), pp. 430-458.

Roca, Jordi, Montserrat Soronellas y Yolanda Bodoque (20I2), "Migraciones por amor: diversidad y complejidad de las migraciones de mujeres", Papers: Revista de Sociologia, 97(3), pp. 685-707. doi:10.5565/rev/papers/ v97n3.355.

Roca, Jordi (2016),"De sur a norte, de norte a sur: el balance laboral de mujeres cualificadas migrantes por amor", Revista Andaluza de Antropología, II, Pp. 92-I2O.

Ryan, Louise, Rosemary Sales, Mary Tilki y Bernadetta Siara (2009), "Family strategies and transnational migration: recent polish migrants in London", Journal of Ethnic and Migration Studies, 35(I), pp. 61-77. doi: I0.1080/13691830802489176.

Scott, Sam (2006),"The social morphology of skilled migration: the case of the British middle class in Paris", Journal of Ethnic and Migration Studies, 32(7), pp. IIO5-II29. doi:10.1080/13691830600821802

Silvey, Rachel (2007), "Mobilizing piety: gendered morality and Indonesian-Saudi transnational migration", Mobilities, 2(2), pp. 219-229. doi:10.1080/17450100701381565.

Svasek, Maruska (2010), "On the move: emotions and human mobility", Journal of Ethnic and Migration Studies, 36(6), pp. 865-880. doi:10.1080/13691831003643322.

Walsh, Katie (2007), "It got very debauched, very Dubai!': performances of heterosexuality amongst single British expatriates", Social and Cultural Geography, 8(4), pp. 507-535. doi:10.1080/14649360701529774.

Walsh, Katie (2009), "Geographies of the heart in transnational spaces: love and the intimate lives of british migrants in Dubai", Mobilities, 4(3), pp. 427-445. doi:10.1080/17450100903195656.

Walsh, Katie (2012),"Emotion and migration: British transnationals in Dubai", Environment and Planning D: Society and Space, 30(I), pp. 43-59. doi:10.1068/di2409.

Wood, Nichola y Louise Waite (2011), "Scales of belonging", Emotion, Space and Society, 4(4), pp. 20I-202, doi: I0.10I6/j.emospa.201I.06.005.

Yeoh, Brenda S.A. y Louisa-May Khoo (1998), "Home, work and community: skilled international migration and expatriate women in Singapore", International Migration, 36(2), pp. 159-I86. doi:I0.IIII/I468-2435.0004I. 
Anna Ortiz Guitart es doctora en Geografía por la Universidad Autónoma de Barcelona. Se desempeña como profesora titular del departamento de Geografía de la Universidad Autónoma de Barcelona. Sus investigaciones se centran en la geografía feminista y las geografías de la infancia y la juventud, y participa activamente en proyectos de investigación españoles e internacionales. Entre sus publicaciones recientes se encuentran: Anna Ortiz, Maria Prats y Mireia Baylina (2016),"Teenagers' sense of neigbourhood in Barcelona”, en Karen Nairn, Peter Kraftl y Tracey Skelton (eds.), Space, Place and Environment, Singapur, Springer, pp. 249-268; Anna Ortiz y Maria Dolores Garcia Ramón (2016), "Nuevas tendencias en la geografía de género en España: una revisión de investigaciones publicadas en el último decenio”, en María Verónica Ibarra García y Irma Escamilla-Herrera (coords.), Geografías feministas de diversas latitudes. Orígenes, desarrollo y temáticas contemporáneas, Ciudad de México, unam, pp. 95-122; y Anna Ortiz y Cristóbal Mendoza (2016).“Jóvenes doctorandos europeos y latinoamericanos en Barcelona: experiencias migratorias y vivencias en la ciudad", Finisterra. Revista Portuguesa de Geografia, 5I(IO2), pp. 8I-IOI.

Citar como: Ortiz Guitart, Ana (2018), "Emociones, amor y experiencias migratorias de españoles e italianos calificados en México", Iztapalapa. Revista de Ciencias Sociales y Humanidades, núm. 84, año 39, enero-junio de 2018, ISSN: 2007-9176; pp. I29-I56. Disponible en <http://revistaiztapalapa.izt. uam.mx/index.php/izt/issue/archive $>$. 